\title{
Constituents of Crinoidea. 2. Isolation and Structure of the Novel Type Gangliosides from the Feather Star Comanthus japonica
}

\author{
Kazuyoshi Arao, Masanori InagaKi, and Ryuichi Higuchi* \\ Graduate School of Pharmaceutical Sciences, Kyushu University, 3-1-1 Maidashi, Higashi-ku, Fukuoka 812-8582, Japan. \\ Received December 6, 2000; accepted March 6, 2001
}

\begin{abstract}
Two novel type gangliosides CJP2 and CJP3 have been obtained from the feather star Comanthus japonica. On the basis of methylation linkage analysis combined with ammonolysis and other chemical and spectroscopic evidence, the chemical structures of CJP2 and CJP3 were determined to be $\alpha$-9-O-Me-NeuGc-(2 $\rightarrow 3)$-inositolphosphoceramide and $\alpha-9-O$-Me-NeuGc- $(2 \rightarrow 11)-\alpha-9-O$-Me-NeuGc-(2 $\rightarrow 3)$-inositolphosphoceramide, respectively. These gangliosides are unique in that they are inositolphosphoceramide derivatives possessing sialic acid; such gangliosides have not previously been identified. The presence of 9-O-methyl- $N$-glycolyl-neuraminosyl residues is also unique in naturally occurring gangliosides.
\end{abstract}

Key words echinodermata; feather star; ganglioside; glycosphingolipid; inositolphosphoceramide; 9-O-methyl- $N$-glycolyl-neuraminic acid

A series of studies on the isolation and structure elucidation of biologically active glycosphingolipids (GSLs) from the echinodermata has been performed in our laboratory. ${ }^{1)}$ In the study of the GSLs of the feather star, we reported on the isolation and structure of a D-myo-inositol-1-O-phosphoceramide, CJP1, from Comanthus japonica. ${ }^{2)}$ Continuing this work, the more polar GSLs from C. japonica were isolated and characterized. In this paper, we report on the isolation and structure of the novel type gangliosides, tentatively called CJP2 and CJP3, from the whole bodies of C. japonica.

The water-soluble lipid fraction, obtained from the $\mathrm{CHCl}_{3} / \mathrm{MeOH}$ extract of the whole bodies of $C$. japonica, was subjected to reversed-phase and subsequently normalphase column chromatography to give CJP2 and CJP3. They showed a single spot on normal-phase TLC and exhibited a positive reaction with Dittmer-Lester reagent, ${ }^{3)}$ which indicated the presence of a phosphate group. In their IR spectra, strong hydroxyl, amide and phosphate absorption was observed. When CJP2 and CJP3 were hydrolyzed with 5\% acetic acid, CJP1, D-myo-inositol-1- $O$-phosphoceramide, was obtained from both compounds. Therefore, CJP2 and CJP3 were suggested to be the derivatives of CJP1.

Structure of CJP2 In the negative ion FAB-MS spectrum, CJP2 showed quasi-molecular ion peaks due to $(\mathrm{M}-\mathrm{H})^{-}$at $m / z 1155$ and 1183 together with fragment ion peaks similar to those of $\mathrm{CJP}^{2)}$ as shown in Fig. 1. The loss of 321 mass units from the molecular ion suggested the existence of a monomethylated $\mathrm{N}$-glycolyl-neuraminic acid residue.

The structure of the sialic acid residue in CJP2 was analyzed as follows. CJP2 was methylated with $\mathrm{CD}_{3} \mathrm{I}$ according to the Ciucanu and Kerek method ${ }^{4}$ and afforded the perdeuteromethylated product. The product was methanolyzed, and the methanolysate was acetylated to give the sialic acid derivative. GC-MS analysis of the sialic acid derivative revealed the presence of terminal 9-O-methylated $\mathrm{N}$-glycolylneuraminic acid (9-O-Me-NeuGc) residue as shown in Fig. 2A.

The position of the 9-O-Me-NeuGc linkage site to the myo-inositol part was elucidated by methylation linkage analysis combined with ammonolysis. ${ }^{5)}$ The permethylated CJP2 was hydrolyzed with $\mathrm{NH}_{4} \mathrm{OH}$ to give the partially methylated inositol derivative. GC-MS analysis of its TMS ether revealed that it was tetramethylated. In the ${ }^{1} \mathrm{H}-\mathrm{NMR}$ spectrum of the tetramethylated inositol, four kinds of oxymethin and three kinds of methoxyl proton signals were observed and could be assigned as shown in Table 1 on the basis of $J$ values, which indicated the symmetrical structure of the tetramethylated inositol. Furthermore, the NOE correlations of methoxyl groups and oxymethin proton signals (Fig. 3) revealed that the inositol derivative was 2,4,5,6tetramethylated myo-inositol. Consequently, 9-O-Me-NeuGc residue must be linked at the $\mathrm{C} 3-\mathrm{OH}$ group of the inositol part as shown in Fig. 1.

The anomeric configuration of 9-O-Me-NeuGc residue was determined as below. When CJP2 was subjected to mild alkaline hydrolysis with $1 \mathrm{~N} \mathrm{KOH}$, the sugar part and ceramide (CJP2Cer) were obtained (Fig. 1). In the ${ }^{1} \mathrm{H}-\mathrm{NMR}$ spectrum of this sugar part, the signal due to $\mathrm{H}-3$ eq of $9-\mathrm{O}-$ Me-NeuGc was observed at $2.73 \mathrm{ppm}(1 \mathrm{H}, \mathrm{dd}, J=12.5$, $4.7 \mathrm{~Hz}$ ), which suggests the $\alpha$-configuration of $9-O-\mathrm{Me}-$ NeuGc. $\left.{ }^{6}\right)$ This part of CJP2 was therefore characterized as $\alpha$ 9-O-Me-NeuGc-( $\rightarrow 3)$-inositolphosphate.

Next, the detailed structure of the ceramide moiety was examined using CJP2Cer obtained as above. When CJP2Cer was methanolyzed, fatty acid methyl ester (FAM) and the
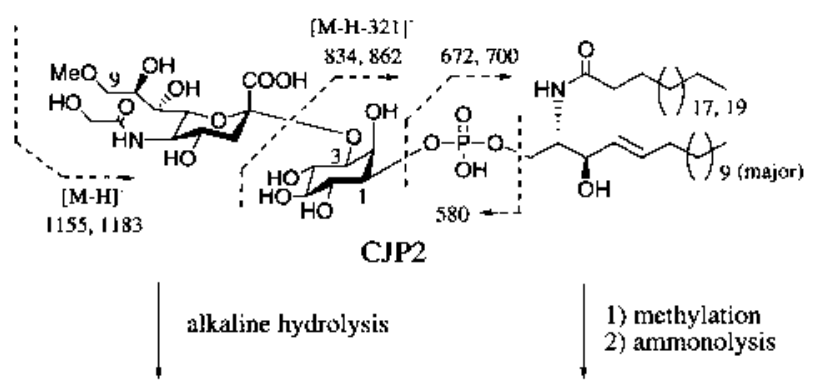

ceramide (CJP2Cer)
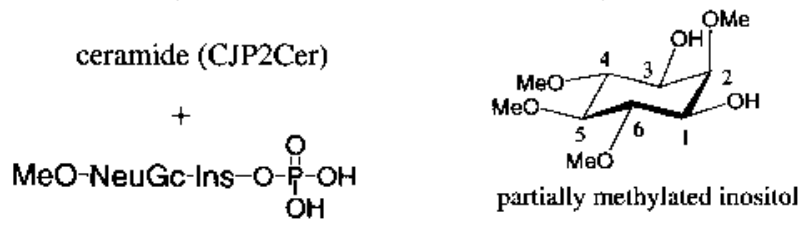

Fig. 1. Structure of CJP2 


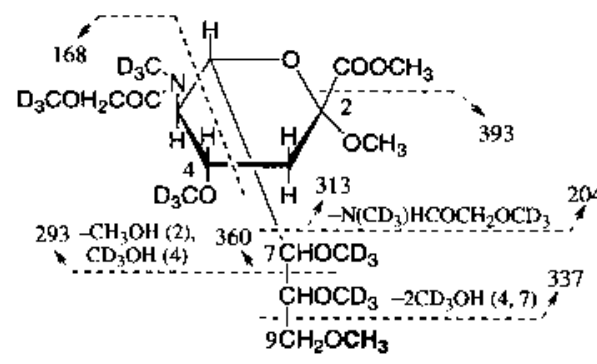

A: terminal 9-O-Me-NeuGc

Fig. 2. Positive Ion EI Mass Spectral Fragmentation of NeuGc Derivatives
Table 1. ${ }^{1} \mathrm{H}-\mathrm{NMR}$ Data of Tetramethylated Inositol ( $\delta$ Values in $\left.\mathrm{CDCl}_{3}\right)$

\begin{tabular}{lll}
\hline \hline & \multicolumn{2}{c}{$\begin{array}{c}\text { Tetramethylated inositol derived from } \\
\text { CJP2 } 2\end{array}$} \\
\hline $\mathrm{H}-1,3$ & $3.39(2 \mathrm{H}, \mathrm{brd}, 10.5)$ & $3.39(2 \mathrm{H}, \mathrm{dd}, 9.5,2.8)$ \\
$\mathrm{H}-2$ & $3.71(1 \mathrm{H}, \mathrm{t}, 2.8)$ & $3.71(1 \mathrm{H}, \mathrm{t}, 2.8)$ \\
$\mathrm{H}-4,6$ & $3.29(2 \mathrm{H}, \mathrm{t}, 9.4)$ & $3.29(2 \mathrm{H}, \mathrm{t}, 9.5)$ \\
$\mathrm{H}-5$ & $2.96(1 \mathrm{H}, \mathrm{t}, 9.0)$ & $2.96(1 \mathrm{H}, \mathrm{t}, 9.0)$ \\
$O-\mathrm{Me}$ & $3.59(3 \mathrm{H}, \mathrm{s})$ & $3.59(3 \mathrm{H}, \mathrm{s})$ \\
& $3.63(6 \mathrm{H}, \mathrm{s})$ & $3.63(6 \mathrm{H}, \mathrm{s})$ \\
& $3.64(3 \mathrm{H}, \mathrm{s})$ & $3.64(3 \mathrm{H}, \mathrm{s})$ \\
\hline
\end{tabular}

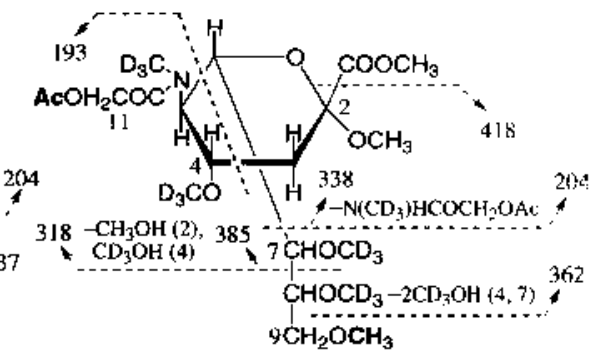

B: 11 linked 9-O-Me-NeuGc

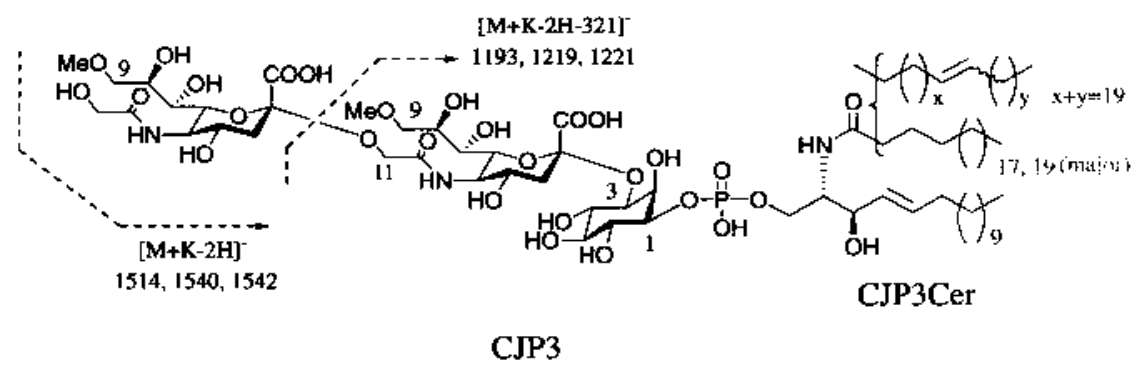

Fig. 4. Structure of CJP3

long chain base (LCB) mixture were obtained. GC-MS analysis of the FAM mixture indicated the presence of $\mathrm{C}_{22: 0}$ and $\mathrm{C}_{24: 0}$ normal fatty acids. On the other hand, the LCB mixture was converted to their TMS ether and analyzed by GC-MS. The result showed that the LCB mixture was composed of $\mathrm{C}_{16: 1}$ sphingosine as major component, and a small amount of $\mathrm{C}_{16: 0}$ and $\mathrm{C}_{18: 0}$ phytosphingosines.

The relative stereochemistry of CJP2Cer could be characterized as 2,3-erythro- $4 E$, because the ${ }^{1} \mathrm{H}-\mathrm{NMR}$ spectrum was in good agreement with that of the ceramide obtained from the gorgonian Acabaria undulata ${ }^{7}$ possessing 2,3-erythro- $4 E$ configuration. Furthermore, in the ${ }^{13} \mathrm{C}-\mathrm{NMR}$ spectrum of CJP2, the signals of the terminal methyl group are observed at $13.7 \mathrm{ppm}$, which indicates both long alkyl chains are straight chains.

Consequently, if LCB and NeuGc are assumed to belong to the most commonly found D-erythro $(2 S, 3 R)$ and $\mathrm{D}$ series, and $m y o$-inositol-1-O-phosphate is also assumed to be D-series, as true of the co-existing CJP1, then CJP2 is $\alpha$-9-O-MeNeuGc-(2 $\rightarrow 3$ )-inositolphosphoceramide as shown in Fig. 1.

Structure of CJP3 In the negative ion FAB-MS spectrum, CJP3 revealed the quasi-molecular ion peaks due to $(\mathrm{M}+\mathrm{K}-2 \mathrm{H})^{-}$at $m / z 1514,1540,1542$ (Fig. 4), which indicate CJP3 contains one additional mole of monomethylated
$\mathrm{N}$-glycolyl-neuraminic acid compared with CJP2. The structure of these sialic acids and the linkage sites of the sialic acid and inositol residues were analyzed in the same manner as CJP2, as follows.

GC-MS analysis of sialic acid derivatives, prepared from perdeuteromethylated CJP3, revealed the existence of terminal $9-\mathrm{O}-\mathrm{Me}-\mathrm{NeuGc}$ and 11 -linked $9-\mathrm{O}-\mathrm{Me}-\mathrm{NeuGc}$ as shown in Fig. 2A and 2B. Therefore, 9-O-Me-NeuGc must be linked at $\mathrm{C} 11-\mathrm{OH}$ of another 9-O-Me-NeuGc residue (Fig. 4). The inositol derivative prepared from permethylated CJP3 was identified as 2,4,5,6-tetramethylated myo-inositol by the ${ }^{1} \mathrm{H}$ NMR and NOESY spectra, which suggested that $9-O-\mathrm{Me}-$ NeuGc residue was linked at $\mathrm{C} 3-\mathrm{OH}$ of the inositol part as true of CJP2. In the ${ }^{13} \mathrm{C}-\mathrm{NMR}$ spectrum of CJP3, two anomeric carbon signals due to two sialic acid residues were observed at $\delta 99.8$ and 100.3 , indicating their $\alpha$-configurations. ${ }^{8)}$ Consequently, the sugar part of CJP3 was determined to be $\alpha-9-O-\mathrm{Me}-\mathrm{NeuGc}-(2 \rightarrow 11)-\alpha-9-O-\mathrm{Me}-\mathrm{NeuGc}-(2 \rightarrow 3)-$ inositolphosphate.

For the analysis of the ceramide moiety, CJP3Cer was obtained by means of alkaline hydrolysis of CJP3. CJP3Cer was methanolyzed and FAM and TMS ether of LCB were analyzed by GC-MS. The results indicated the presence of $\mathrm{C}_{22: 0}, \mathrm{C}_{24: 0}$, and $\mathrm{C}_{24: 1}$ normal fatty acid and $\mathrm{C}_{16: 1}$ sphingosine 
as major components. The relative stereochemistry of ceramide was determined to have 2,3-erythro- $4 E$ configuration with the aid of the ${ }^{1} \mathrm{H}-\mathrm{NMR}$ spectrum of CJP3Cer.

Consequently, if LCB, NeuGc and myo-inositol-1-O-phosphate are assumed to belong to the D-erythro $(2 S, 3 R)$ and $\mathrm{D}$ series as CJP2, CJP3 is characterized to be $\alpha-9-O-\mathrm{Me}-$ NeuGc- $(2 \rightarrow 11)-\alpha$-9-O-Me-NeuGc-( $2 \rightarrow 3)$-inositolphosphoceramide as described in Fig. 4.

Many kinds of gangliosides of echinodermata have been obtained from species of starfish, sea cucumber, sea urchin and brittle star. This is the first report of isolation and characterization of gangliosides from the feather star. The gangliosides obtained this time, CJP2 and CJP3, are specially novel in the respect that they are inositolphosphoceramide derivatives containing a sialic acid residue. To the best of our knowledge, such unique gangliosides have not previously been reported. Furthermore, the presence of the 9-O-methyl$\mathrm{N}$-glycolyl-neuraminic acid residues is also unique in the naturally occurring gangliosides. The biological activity of these gangliosides will be examined.

\section{Experimental}

Melting points were determined on a micromelting point apparatus (Yanaco MP-3) without correction. IR spectra were obtained on a Jasco FT/IR-410 infrared spectrophotometer. ${ }^{1} \mathrm{H}$ - and ${ }^{13} \mathrm{C}-\mathrm{NMR}$ spectra were recorded on a Jeol GX-270 spectrometer $(270$ and $67.8 \mathrm{MHz})$ or a Varian Unity spectrometer (500 and $125 \mathrm{MHz}$ ). Negative ion FABMS spectra were acquired with a Jeol SX/SX102A tandem mass spectrometer (xenon atom beam, $5 \mathrm{kV}$; ion source accelerating potential, $10 \mathrm{kV}$; matrix, triethanol amine). GC-MS was taken with a Shimadzu QP-5050A [EI mode; ionization potential: $70 \mathrm{eV}$; column: high resolution capillary column $(\phi 0.25 \mathrm{~mm} \times$ $30 \mathrm{~m}$ ), liquid phase: TC-1701; carrier gas: $\mathrm{He}(100 \mathrm{kPa}$, split mode)], or a Shimadzu QP-1000 [EI mode; ionization potential: $70 \mathrm{eV}$; separator and ionsource temperature $250^{\circ} \mathrm{C}$; column: a glass column $(\phi 2.6 \mathrm{~mm} \times 1.1 \mathrm{~m})$ packed with $2 \%$ OV-17 on Chromosorb W (80-100 mesh) or capillary column, Shimadzu CBP-10-W12-100 $(\phi 0.53 \mathrm{~mm} \times 12 \mathrm{~m})$ carrier gas, $\mathrm{He}$ $(30 \mathrm{ml} / \mathrm{min})]$.

Separation of CJP2 and CJP3 Whole bodies of the feather star Comanthus japonica (7.6 kg), collected in 1995 at Koinoura, Fukuoka Prefecture, Japan, were homogenized and extracted with $\mathrm{CHCl}_{3} / \mathrm{MeOH}(1: 2,81$, three times). The $\mathrm{CHCl}_{3} / \mathrm{MeOH}$ solution was concentrated in vacuo to give an aqueous suspension (11). The suspension was diluted with $\mathrm{H}_{2} \mathrm{O}(21)$ and extracted with AcOEt $/ n-\mathrm{BuOH}(2: 1)$ for separation of less polar lipids. The aqueous layer was washed with $n$ - $\mathrm{BuOH}$ saturated with $\mathrm{H}_{2} \mathrm{O}$, and concentrated in vacuo to 11 . Then, 11 of $\mathrm{MeOH}$ was added to the aqueous layer and the mixture was chromatographed on reversed-phase column chromatography [Cosmosil $140 \mathrm{C}_{18}$-PREP (Merck), solvent $80 \% \mathrm{MeOH}, 100 \% \mathrm{MeOH}$ and $\left.\mathrm{CHCl}_{3} / \mathrm{MeOH}(3: 7)\right]$. The $100 \% \mathrm{MeOH}$ and $\mathrm{CHCl}_{3} / \mathrm{MeOH}(3: 7)$ eluate were combined and concentrated in vacuo to give a residue $(4.1 \mathrm{~g})$, which was then chromatographed on silica gel [silica gel 60 (70-230 mesh, Merck), solvent $\mathrm{CHCl}_{3} / \mathrm{MeOH} / \mathrm{H}_{2} \mathrm{O}(6.5: 3.5: 0.2,6.5: 3.5: 0.3,6.5: 3.5$ : $0.5,6.5: 3.5: 0.55,6: 4: 0.7,6: 4: 0.85,6: 4: 1,5: 5: 1)]$ to give seven fractions. CJP2 $(170.6 \mathrm{mg})$ was obtained from frs. 2 and 3 with silica gel column chromatography [Iatrobeads (6RS-8060, Iatron Lab.), solvent $\mathrm{CHCl}_{3} /$ $\left.\mathrm{MeOH} / \mathrm{H}_{2} \mathrm{O}(6: 4: 0.35)\right]$. CJP3 $(568.5 \mathrm{mg})$ was obtained from frs. 3 and 4 [silica gel 60 (230- 400 mesh), solvent $\mathrm{CHCl}_{3} / \mathrm{MeOH} / \mathrm{H}_{2} \mathrm{O}(7: 3: 0.6)$ ]. It was detected with $5 \% \mathrm{H}_{2} \mathrm{SO}_{4} / \mathrm{MeOH}$ or Dittmer-Lester reagent on silica gel TLC [solvent $\mathrm{CHCl}_{3} / \mathrm{MeOH} / \mathrm{H}_{2} \mathrm{O}(6: 4: 1)$ ], $R f=0.50$ (CJP2), 0.40 (CJP3).

CJP2: Amorphous powder. $\mathrm{mp} 203-208^{\circ} \mathrm{C}$. IR $(\mathrm{KBr}) \mathrm{cm}^{-1}$ : $3365(\mathrm{OH})$, 2923, 2853 (alkyl chain), 1646, 1554 (amide), 1227 (phosphate). Negative ion FAB-MS $m / z$ : 79, 97 (phosphate), 241, 259, 580 (sugar part), 672, 700 $(\mathrm{M}-\mathrm{H}-162-321)^{-}, 834,862(\mathrm{M}-\mathrm{H}-321)^{-}, 1155,1183(\mathrm{M}-\mathrm{H})^{-} .{ }^{13} \mathrm{C}-$ NMR $\left[\mathrm{CDCl}_{3} / \mathrm{CD}_{3} \mathrm{OD}(3: 1)\right] \delta: 13.7$ (terminal methyl groups), 29.3 (alkyl chain).

CJP3: Amorphous powder. mp 203-208 ${ }^{\circ} \mathrm{C}$. IR $(\mathrm{KBr}) \mathrm{cm}^{-1}: 3854(\mathrm{OH})$, 2923, 2853 (alkyl chain), 1636, 1558 (amide), 1231 (phosphate). Negative ion FAB-MS $m / z$ : 79, 97 (phosphate), 241, 259, 580 (sugar part), 1193, $1219,1221(\mathrm{M}+\mathrm{K}-2 \mathrm{H}-321)^{-}, 1514,1540,1542(\mathrm{M}+\mathrm{K}-2 \mathrm{H})^{-} .{ }^{13} \mathrm{C}-\mathrm{NMR}$ $\left[\mathrm{C}_{5} \mathrm{D}_{5} \mathrm{~N} / \mathrm{D}_{2} \mathrm{O}(20: 7)\right] \delta: 14.0$ (terminal methyl groups), 29.6 (alkyl chain), 99.8, 100.3 (Neu5Gc9Me C-2).
Methylation (Trideuteriomethylation) of CJP2 (Ciucanu and Kerek Method) $\mathrm{NaOH} / \mathrm{DMSO}$ suspension $(0.25 \mathrm{ml})$, which was prepared from powdered $\mathrm{NaOH}(40 \mathrm{mg})$ and DMSO $(1 \mathrm{ml})$, and $\mathrm{CD}_{3} \mathrm{I}(0.25 \mathrm{ml})$ was added to CJP2 $(0.8 \mathrm{mg})$, and the mixture was sonicated for $30 \mathrm{~min}$. The reaction mixture was diluted with $\mathrm{H}_{2} \mathrm{O}$ and extracted with $\mathrm{CHCl}_{3}$ three times to give perdeuteromethylated CJP2.

Preparation and GC-MS Analysis of Acetate of Partially Trideuteromethylated Sialic Acid from Perdeuteromethylated CJP2 Perdeuteromethylated CJP2 was methanolyzed with $5 \% \mathrm{HCl}$ in $\mathrm{MeOH}$ $(1 \mathrm{ml})$ at $85^{\circ} \mathrm{C}$ for $12 \mathrm{~h}$ in a small-volume sealed vial, and dried with a $\mathrm{N}_{2}$ stream. The reaction mixture was heated with $\mathrm{Ac}_{2} \mathrm{O} /$ pyridine $(1: 1,0.5 \mathrm{ml})$ at $85^{\circ} \mathrm{C}$ for $2 \mathrm{~h}$, and dried with a $\mathrm{N}_{2}$ stream. The residue was subjected to GCMS (QP-1000, capillary column) [column temperature: $180-250^{\circ} \mathrm{C}$ (rate of temperature increase $\left.\left.4{ }^{\circ} \mathrm{C} / \mathrm{min}\right)\right]: t_{\mathrm{R}}[\mathrm{min}]=5.7, \mathrm{~m} / \mathrm{z}: 168,204,293,313$, $337,360,393$ [methyl $N$-glycolyl- $N$-trideuteromethyl-2,9-di- $O$-methyl4,7,8,11-tetra- $O$-trideuteromethyl-neuraminate (from terminal 9-O-MeNeuGc)].

Methylation of CJP2 (Ciucanu and Kerek Method) $\mathrm{NaOH} / \mathrm{DMSO}$ suspension $(0.5 \mathrm{ml})$ and $\mathrm{CH}_{3} \mathrm{I}(0.1 \mathrm{ml})$ were added to CJP2 $(7.9 \mathrm{mg})$, and the mixture was sonicated for $30 \mathrm{~min}$. The reaction mixture was diluted with $\mathrm{H}_{2} \mathrm{O}$, acidified with $2 \mathrm{~N} \mathrm{HCl}$, and extracted with $\mathrm{CHCl}_{3}$ three times to give permethylated CJP2.

Ammonolysis of Permethylated CJP2 Permethylated CJP2 was heated with $\mathrm{NH}_{4} \mathrm{OH}(1.5 \mathrm{ml})$ for $12 \mathrm{~h}$ at $150^{\circ} \mathrm{C}$ in a sealed pressure tube $(25.4$ $\mathrm{mm} \times 10.2 \mathrm{~cm}$, Ace Glass Incorporated). The reaction mixture was evaporated and dried with an air stream to give the residue containing partially methylated inositol derivative. The residue was chromatographed on silica gel [Iatrobeads, solvent $\mathrm{CHCl}_{3}$ /acetone $(6.5: 3.5)$ ] to give an inositol derivative (2,4,5,6-tetramethylated $m y o$-inositol, $0.21 \mathrm{mg}), R f=0.16$ [silica gel TLC, $\mathrm{CHCl}_{3}$ /acetone $\left.(6.5: 3.5)\right]$.

2,4,5,6-Tetramethylated myo-Inositol: ${ }^{1} \mathrm{H}-\mathrm{NMR}\left(\mathrm{CDCl}_{3}\right) \delta: 3.39(2 \mathrm{H}, \mathrm{dd}$, $J=9.5,2.8 \mathrm{~Hz}, \mathrm{H}-1,3), 3.71(1 \mathrm{H}, \mathrm{t}, J=2.8 \mathrm{~Hz}, \mathrm{H}-2), 3.29(2 \mathrm{H}, \mathrm{t}, J=9.5 \mathrm{~Hz}$, $\mathrm{H}-4,6), 2.96(1 \mathrm{H}, \mathrm{t}, J=9.0 \mathrm{~Hz}, \mathrm{H}-5), 3.59(3 \mathrm{H}, \mathrm{s}, O-\mathrm{Me}), 3.63(6 \mathrm{H}, \mathrm{s}, O-$ $\mathrm{Me}), 3.64(3 \mathrm{H}, \mathrm{s}, O-\mathrm{Me})$. NOESY: see Fig. 3. The inositol derivative $(0.1 \mathrm{mg})$ was heated with 1 -(trimethylsilyl)imidazole/pyridine $(1: 1,10 \mu \mathrm{l})$ for $15 \mathrm{~min}$ at $70^{\circ} \mathrm{C}$ and the reaction mixture was subjected to GC-MS (QP5050A) [column temperature: $100^{\circ} \mathrm{C}(2 \mathrm{~min})-250^{\circ} \mathrm{C}$ (rate of temperature increase $\left.\left.5^{\circ} \mathrm{C} / \mathrm{min}\right)\right]$. The results were as follows: $2,4,5,6$-tetramethylated inositol TMS ether: $t_{\mathrm{R}}[\mathrm{min}]=17.3, \mathrm{~m} / z$ (rel. int. \%) $380\left(\mathrm{M}^{+}, 1.7\right), 217$ (32.6), 202 (46.9), 191 (17.0), 189 (22.9), 172 (16.6), 159 (83.2), 146 (29.9), 144 (49.6), 133 (96.1), 114 (37.6), 101 (100), 89 (75.5), 75 (98.7).

Alkaline Hydrolysis of CJP2 CJP2 was hydrolyzed with $1 \mathrm{~N} \mathrm{KOH}$ at $35^{\circ} \mathrm{C}$ for $31 \mathrm{~h}$. Hydrolysate was neutralized with Dowex $50 \mathrm{~W}-\mathrm{X} 8\left(\mathrm{H}^{+}\right)$resin, and partitioned between $\mathrm{H}_{2} \mathrm{O}$ and $\mathrm{CHCl}_{3}$. The $\mathrm{H}_{2} \mathrm{O}$ layer was diluted with the same quantity of $\mathrm{MeOH}$, and then passed through Cosmosil $140 \mathrm{C}_{18}{ }^{-}$ PREP (solvent $50 \% \mathrm{MeOH}$ ). The eluate was evaporated in vacuo to give a residue and the residue was applied to a Sephadex LH-20 column (solvent $50 \% \mathrm{MeOH}$ ) to give the sugar part of $\mathrm{CJP} 2$. The $\mathrm{CHCl}_{3}$ layer was evaporated in vacuo and the residue was purified by silica gel column chromatography [Iatrobeads, solvent $\mathrm{CHCl}_{3} / \mathrm{MeOH}(9: 1)$ ] to give CJP2Cer.

Sugar Part of CJP2: Negative FAB-MS $m / z: 580(\mathrm{M})^{-}, 562\left(\mathrm{M}-\mathrm{H}_{2} \mathrm{O}\right)^{-}$, 259, 97, 79. ${ }^{1} \mathrm{H}-\mathrm{NMR}\left(\mathrm{D}_{2} \mathrm{O}\right) \delta: 2.73(\mathrm{dd}, J=12.5,4.7 \mathrm{~Hz}, 9-O-\mathrm{Me}-\mathrm{NeuGc}$ $\left.\mathrm{H}-3_{\mathrm{eq}}\right), 1.80\left(\mathrm{t}, J=12.1 \mathrm{~Hz}, 9-O-\mathrm{Me}-\mathrm{NeuGc} \mathrm{H}-3_{\mathrm{ax}}\right)$.

CJP2Cer: ${ }^{1} \mathrm{H}-\mathrm{NMR}\left(\mathrm{CDCl}_{3}\right) \delta: 3.70(\mathrm{~m}), 3.91(\mathrm{~m}, \mathrm{H}-2), 3.96(\mathrm{dd}, J=13.5$, $3.3 \mathrm{~Hz}, \mathrm{H}-1$ ), 4.33 (br s, H-3), 5.53 (dd, $J=15.3,6.4 \mathrm{~Hz}, \mathrm{H}-4), 5.78$ (dt, $J=14.8,7.3 \mathrm{~Hz}, \mathrm{H}-5), 6.22(\mathrm{~d}, J=6.9 \mathrm{~Hz}, \mathrm{NH}), 2.23$ (t, $\left.J=7.6 \mathrm{~Hz}, \mathrm{H}-2^{\prime}\right)$, 1.25 (alkyl chain), 0.88 ( $\mathrm{t}, J=6.6 \mathrm{~Hz}$, terminal methyl groups).

Methanolysis of CJP2Cer CJP2Cer was methanolyzed with $5 \% \mathrm{HCl}$ in $\mathrm{MeOH}$ at $70^{\circ} \mathrm{C}$ for $2 \mathrm{~h}$ in a small-volume sealed vial. The reaction mixture was extracted with $n$-hexane, and the extract was concentrated in vacuo to yield a mixture of fatty acid methyl esters (FAM). The $\mathrm{MeOH}$ layer was neutralized with $\mathrm{Ag}_{2} \mathrm{CO}_{3}$, filtered, and the filtrate was concentrated in vacuo to give a mixture of long chain bases (LCB).

GC-MS Analysis of FAM from CJP2Cer The FAM mixture derived from CJP2Cer was subjected to GC-MS (QP-1000, OV-17) [column temperature $150-250{ }^{\circ} \mathrm{C}$ (rate of temperature increase $8^{\circ} \mathrm{C} / \mathrm{min}$ )]. The results were as follows: FAM-1 (methyl docosanoate), $t_{\mathrm{R}}[\mathrm{min}]$ (ratio of peak areas): 11.3 (34), $m / z: 354(\mathrm{M})^{+}, 311(\mathrm{M}-43)^{+}$; FAM-2 (methyl tetracosanoate), $t_{\mathrm{R}}: 13.3$ (66), $m / z: 382(\mathrm{M})^{+}, 339(\mathrm{M}-43)^{+}$.

GC-MS Analysis of TMS Ethers of LCB from CJP2Cer The mixture of LCB derived from CJP2Cer was heated with 1-(trimethylsilyl)imidazole/pyridine $(1: 1,50 \mu \mathrm{l})$ for $10 \mathrm{~min}$ at $70^{\circ} \mathrm{C}$ and the reaction mixture was subjected to GC-MS (QP-1000, OV-17) [column temperature 180$250^{\circ} \mathrm{C}$ (rate of temperature increase $8^{\circ} \mathrm{C} / \mathrm{min}$ )]. The results were as follows: 
LCB-1 (2-amino-hexadec-4-ene-1,3-diol), $t_{\mathrm{R}}$ [min] (ratio of peak areas): 4.5 (65), $m / z: 312(\mathrm{M}-103)^{+}, 310(\mathrm{M}-105)^{+}, 283(\mathrm{M}-132)^{+}, 132$; LCB-2 (2amino-hexadecane-1,3,4-triol), $t_{\mathrm{R}}: 5.6(17), \mathrm{m} / \mathrm{z}: 312(\mathrm{M}-193)^{+}, 271$ $(\mathrm{M}-234)^{+}, 204,132$; LCB-3 (2-amino-octadecane-1,3,4-triol), $t_{\mathrm{R}}$ : 7.3 (17), $m / z: 340(\mathrm{M}-193)^{+}, 299(\mathrm{M}-234)^{+}, 204,132$.

Preparation and GC-MS Analysis of Acetate of Partially Trideuteromethylated Sialic Acid Derived from CJP3 CJP3 was trideuteromethylated according to the Ciucanu and Kerek method, then methanolyzed and acetylated in the same manner as for CJP2. The residue was subjected to GC-MS (QP-5050A) [column temperature $200^{\circ} \mathrm{C}(2.0$ min) $-250^{\circ} \mathrm{C}$ (rate of temperature increase $2.5^{\circ} \mathrm{C} / \mathrm{min}$ )]: $t_{\mathrm{R}}[\mathrm{min}]=23.1$, $\mathrm{m} / z: \quad 168, \quad 204,293, \quad 313, \quad 337, \quad 360,393$ [methyl $N$-glycolyl- $N$ trideuteromethyl-2,9-di- $O$-methyl-4,7,8,11-tetra- $O$-trideuteromethyl-neuraminate (from terminal 9-O-Me-NeuGc)]: $t_{\mathrm{R}}[\mathrm{min}]=29.2, \mathrm{~m} / \mathrm{z}: 193,204$, $318,362,385,418$ [methyl $N$-glycolyl- $N$-trideuteromethyl-11- $O$-acetyl-2,9di- $O$-methyl-4,7,8-tri- $O$-trideuteromethyl-neuraminate (from 11-linked 9-O$\mathrm{Me}-\mathrm{NeuGc})]$.

Methylation Linkage Analysis Combined with Ammonolysis of CJP3 CJP3 $(10.0 \mathrm{mg})$ was permethylated and ammonolyzed in the same manner as for CJP2. The reaction mixture was evaporated and dried to give a residue containing a partially methylated inositol derivative. The residue was chromatographed on silica gel to give an inositol derivative (2,4,5,6-tetramethylated myo-inositol, $0.45 \mathrm{mg}$ )

Alkaline Hydrolysis of CJP3 CJP3 was hydrolyzed with $1 \mathrm{~N} \mathrm{KOH}$. The hydrolysate was neutralized with $2 \mathrm{~N} \mathrm{HCl}$, and extracted with $\mathrm{CHCl}_{3}$ three times, and evaporated in vacuo. The residue was purified by silica gel column chromatography to give CJP3Cer.

CJP3Cer: ${ }^{1} \mathrm{H}-\mathrm{NMR}\left(\mathrm{CDCl}_{3}\right) \delta: 3.71(\mathrm{dd}, J=11.2,2.6 \mathrm{~Hz}, \mathrm{H}-1), 3.92(\mathrm{~m}$, H-2), 3.96 (dd, $J=11.2,3.3 \mathrm{~Hz}, \mathrm{H}-1$ ), 4.33 (br s, H-3), 5.53 (dd, $J=15.5$, $6.1 \mathrm{~Hz}, \mathrm{H}-4), 5.79$ (dt, $J=15.5,7.4 \mathrm{~Hz}, \mathrm{H}-5), 6.26$ (d, $J=6.3 \mathrm{~Hz}, \mathrm{NH}), 2.23$ (t, $J=7.6 \mathrm{~Hz}, \mathrm{H}-2^{\prime}$ ), 1.25 (alkyl chain), 0.88 (t, $J=6.6 \mathrm{~Hz}$, terminal methyl groups).

Methanolysis of CJP3Cer CJP3Cer was methanolyzed and the reaction mixture was extracted with $n$-hexane. The extract was concentrated in vacuo to yield a mixture of fatty acid methyl esters (FAM). The $\mathrm{MeOH}$ layer was dried with a $\mathrm{N}_{2}$ stream to give a mixture of long chain bases (LCB).

GC-MS Analysis of FAM from CJP3Cer The FAM mixture derived from CJP3Cer was subjected to GC-MS (QP-5050A) [column temperature
$150(2 \mathrm{~min})-250^{\circ} \mathrm{C}$ (rate of temperature increase $\left.\left.5^{\circ} \mathrm{C} / \mathrm{min}\right)\right]$. The results were as follows: FAM-1 (methyl hexadecanoate), $t_{\mathrm{R}}$ [min] (ratio of peak areas) $=12.9(9), m / z: 270(\mathrm{M})^{+}, 227(\mathrm{M}-43)^{+} ;$FAM-2 (methyl octadecanoate), $t_{\mathrm{R}}=16.6(9), m / z: 298(\mathrm{M})^{+}, 255(\mathrm{M}-43)^{+}$; FAM-3 (methyl docosanoate), $t_{\mathrm{R}}=23.5(37), m / z: 354(\mathrm{M})^{+}, 311(\mathrm{M}-43)^{+}$; FAM-4 (methyl tetracosenoate), $t_{\mathrm{R}}=27.8(14), m / z: 380(\mathrm{M})^{+}, 348,349$; FAM-5 (methyl tetracosanoate), $t_{\mathrm{R}}=28.1(24), m / z: 382(\mathrm{M})^{+}, 339(\mathrm{M}-43)^{+}$.

GC-MS Analysis of LCB TMS Ethers from CJP3Cer The mixture of LCB derived from CJP3Cer was trimethylsilylated and the reaction mixture was subjected to GC-MS (QP-5050A) [column temperature 180 ( $2 \mathrm{~min}$ )$250^{\circ} \mathrm{C}$ (rate of temperature increase $5^{\circ} \mathrm{C} / \mathrm{min}$ )]. The results were as follows: LCB-1 (2-amino-hexadec-4-ene-1,3-diol), $\quad t_{\mathrm{R}} \quad[\mathrm{min}]=13.9, \quad \mathrm{~m} / \mathrm{z}: \quad 312$ $(\mathrm{M}-103)^{+}, 310(\mathrm{M}-105)^{+}, 283(\mathrm{M}-132), 132$.

Acknowledgments The authors thank Mr. Y. Tanaka and Ms. Y. Soeda of the Faculty of Pharmaceutical Sciences, Kyushu University, for NMR measurements. This work was supported in part by Grants-in-Aid for Scientific Research No. 09470486 and 12045253 (Priority Areas A) from the Ministry of Education, Science, Sports, Culture and Technology Japan, which are gratefully acknowledged.

\section{References}

1) a) Higuchi R., Inukai K., Zhou J. X., Honda M., Komori T., Tsuji S., Nagai Y., Liebigs Ann. Chem., 1993, 359-366; b) Yamada K., Harada Y., Nagaregawa Y., Miyamoto T., Isobe R., Higuchi R., Eur. J. Org. Chem., 1998, 2519-2525; c) Kawatake S., Inagaki M., Miyamoto T., Isobe R., Higuchi R., ibid., 1999, 765-769; d) Kaneko M., Kisa F., Yamada K., Miyamoto T., Higuchi R., ibid., 1999, 3171-3174.

2) Arao K., Inagaki M., Higuchi R., Chem. Pharm. Bull., 47, 687-689 (1999).

3) Dittmer J. C., Lester R. L., Lipid Res., 5, 126-127 (1964).

4) Ciucanu I., Kerek F., Carbohydr. Res., 131, 209-217 (1984).

5) Barr K., Lester R. L., Biochemistry, 23, 5581—5588 (1984).

6) Dabrowski U., Friebolin H., Brossmer R., Supp M., Tetrahedron Lett., 48, 4637-4640 (1979).

7) Shin J., Seo Y., J. Nat. Prod., 58, 948-953 (1995).

8) Higuchi R., Mori T., Sugata T., Yamada K., Miyamoto T., Eur. J. Org. Chem., 1999, 3175-3178. 